\title{
A new method to determine oxidative stability of vegetable fats and oils at simulated frying temperature
}

Oléagineux, Corps Gras, Lipides. Volume 8, Numéro 1, 82-8, Janvier - Février 2001, Dossier : Deutsche Gesellschaft für Fettwissenschaft - Association française pour l'étude des corps gras

Auteur(s) : Christian GERTZ, S. Parkash KOCHHAR, Chemisches Untersuchungsamt Hagen Pappelstr. 1 D-58099 Hagen, Germany.

Summary : A new procedure at simulated frying conditions in our laboratory was developed to monitor frying stability of fats and oils. Water-conditioned silica was prepared and added to the fresh vegetable oil, which was heated for two hours at $170^{\circ} \mathrm{C}$. The oil stability at frying temperature was then evaluated by determining the amount of formed dimeric triglycerides The results obtained showed that the stability of the vegetable oils at frying temperature could not be explained by the fatty acid composition alone. Corn oil was observed to be more stable than soybean oil, and rapeseed oil was better than olive oil. It was also observed that crude, non-refined oils were found to have a better heat stability than refin-ed oils. To estimate the effectiveness of synthetic and naturally occurring antioxidants, namely various tocopherols, tocopherol acetate and phytosterol fractions, phenolic compounds like quercetin, oryzanol, ferulic acid, gallates, BHT, BHA and other compounds like ascorbic acid 6-palmitate and squalene were added to refined sunflower and rape seed oil, and their oxidative stability at elevated temperature (OSET) values determined. Both linoleic and oleic rich oils gave comparable results for the activity of the various compounds. alpha-tocopherol, tocopherol esters and BHA had low effects on oil stability at frying temperature, while ascorbyl palmitate and some phytosterol fractions were found to have the most stabilizing activity under frying conditions.

Keywords : oxidative stability, heat stability, deep frying, antioxidant, natural components.

\section{ARTICLE}

During deep-frying, the fat and oil decompose forming volatile, non-volatile, monomeric and polymeric, oxidised or non-oxidised compounds. Their amounts and chemical structures depend on the nature of fat or oil used, the temperature, frying time, the food (of what moisture content) being fried, and on the accessibility of air (oxygen). Deep frying is a complex phenomenon where water, oxygen and heat are the main factors, which determine the kinetics of oxidation and polymerisation processes. 
Vegetable oils like soybean, sunflower, corn or rapeseed were often judged very unsuitable for continuous frying due to the content of polyunsaturated fatty acids.

The "bad" assessment of vegetable oils with a high content of polyunsaturated fatty acids is essentially based on methods of tes-ting in which the induction time is used to measure oxidation readiness.

One of the oldest dynamic methods is the Schaal oven test [1], where peroxide value (PV) is determined daily in the fat sample, which is kept in an open glass beaker stored in a thermoregulated oven set at $60^{\circ} \mathrm{C}$. The absorption of oxygen is measured in the method according to Warburg and the oxygen-bomb test. In the classic Swift test [2] or the Active Oxygen method (AOM) (AOCS CD 12-57 - 1981) air is passed through a sample of oil heated at $98^{\circ} \mathrm{C}$ and PV is determined at various intervals. The PV is then plotted against time and the induction time or period is calculated as time between the start-point and the point of intersection obtained by the baseline and the tangent drawn from the curve's inflection.

Despite its widespread use the AOM analysis has many deficiencies and difficulties [3].Therefore, an alternate method based on the measurement of conductance produced by volatile organic acids collected in deionised water has been proposed. The organic acids are stable tertiary oxidation reaction products from heated oils, which are oxidized by air bubbling through them. The method is called Oxidative Stability of Oils (OSI) or Rancimat Method [4, 5]. These officially recommended methods are very popular and are frequently used. The fully automated accelerated tests, normally carried out at $100^{\circ} \mathrm{C}$ to $130^{\circ} \mathrm{C}$, involve the measurement of induction period, i.e. the time during which oil's natural resistance to oxidation due to the presence of naturally occurring antioxidants inhibits oxidation. Often laboratories run the OSI/Rancimat test at higher temperatures to shorten the analysis time for hard fats. This is a dangerous extrapolation, because of the simultaneous formation and degradation of the peroxides at different reaction rates, which are complex functions of temperature [3]. It is recommended to carry out the test only at $100^{\circ} \mathrm{C}$, while above $120^{\circ} \mathrm{C}$ there are chances that volatile low-molecular weight fatty acids, if present, will be lost. Therefore the Rancimat test or OSI method fails when applied to evaluate used deep-frying fats containing short chain oxidised components.

Observations of the results from the Rancimat and Schaal tests indicated an opposite effect for the oxidative stability of several oils measured by the Rancimat method at $120^{\circ} \mathrm{C}$ and the Schaal Oven test at $60^{\circ} \mathrm{C}$. The difference between these two tests is $60^{\circ} \mathrm{C}$ and this influences the oxidation mechanism and degradation rate of the unsaturated fatty acids [6]. Induction time determination by the Rancimat method is based on detection of volatile acids [7] while in the Schaal Oven test procedure the autoxidation products detected are mainly hydroperoxides and to a lesser extent secondary products [8]. Because the oxidation of oils and fats in an excess of oxygen (air) is clearly an exothermal reaction which can be quantified by thermal analysis techniques. Among these, differential scanning calorimetry (DSC) and pressure differential scanning calorimetry (PDSC) seems to be the most useful. Cross [9] achieved a successful correlation between measurements by DSC and the active oxygen method. As the DSC transition temperatures were not sharp enough, now-a-days, the isothermal method PDSC [10] is used as an alternate method to AOM. 
By this method an improved linear correlation is obtain-ed. In PDSC the experiment is carried out at lower temperatures and the heat of transition is more precisely defined.

All tests provide good information about the shelf-life, rancidity and oxidative resistance at normal temperature. These tests aren't how-ever suitable, one wants to check the behaviour of fats and oils at frying conditions or to measure the antioxidative effectiveness of compounds which are volatile by steam such as an antioxidant BHA, organic acids like citric acid. Furthermore, these oxidative stability tests cannot be use to prove the influence protective gas like nitrogen or antifoaming agent.

To sum up, almost all recommended standard methods for oxidative stability are carried out with an excess of oxygen at temperatures, which are totally different from frying conditions. These tests assumed that thermal oxidative changes at $100^{\circ} \mathrm{C}$ or $120^{\circ} \mathrm{C}$ are not different from those at elevated temperatures The large number of "artefacts" in used frying fats indicates that different degradation reactions take place. Therefore it is impossible to extrapolate the data obtained at lower temperature in presence of oxygen for the oil stability at elevated temperature with a reduced contact with air.

Realizing the deficiencies of these oxidative stability tests, some researchers even tried using cotton balls, impregnated with solutions of glucose and different amino acids, which were deep fried at $180^{\circ} \mathrm{C}$ in vegetable oil. In fact, it is very difficult to assess frying oil stability actually without numerous cost-intensive deep-frying tests.

For the laboratory testing purpose, a new procedure is, therefore, developed to estimate the heat stability of vegetable fats and oils under frying conditions and to evaluate the antioxidative efficacy of interesting substances [11].

\section{Method and materials}

Weigh $20 \mathrm{~g}$ of the sample into a glass vessel (outer diameter about $40 \mathrm{~mm}$, capacity $100 \mathrm{ml}$ ). Add $1.0 \mathrm{~g}$ prepared silica gel (Kieselgel 60, 0.063-0.2mm (Merck) is heated for $1 \mathrm{~h}$ at $103^{\circ} \mathrm{C}$, after cooling the water content is adjusted to 10\%) and allow the suspension to stand at ambient temperature for 2 hours, with occasional swirling of the content. After a treatment in an ultrasonic bath for $1 \mathrm{~min}$ the vessel is heated at $170^{\circ} \mathrm{C}$ in an aluminium box for 2 hours. After cooling the oil is filtered. About $50 \mathrm{mg}$ of the sample is diluted with tetrahydrofurane, and the solution is analysed by HPLC system

\section{High performance liquid chromatography (HPLC)}

The following conditions have been found as optimum [12]:

- stationary phase: PL-Gel 100A, 2 x 300 x 7.6mm, 5mum;

- mobile phase: tetrahydrofurane;

- flow: $0.7 \mathrm{ml} / \mathrm{min}$; 
- detector: refractive index detector;

- temperature: (detector and column oven): $35^{\circ} \mathrm{C}$;

- sample injection: 20mu.l.

The retention time of the monomer triglycerides is determined by injecting unheated vegetable oil dissolved in the solvent mixture as the standard solution. Only those peaks are taken into consideration which have a lower retention than the free fatty acids, represented by the peak of heptadecanoic acid. All areas of peaks having a retention time shorter than the retention time for the monomer triglycerides are added up, and this represents the total amount of polymerised (dimer and oligomer) triglycerides. The quantification of the peak areas is achieved by the horizontal base method.

The calculated content (in \%) of the polymerised (especially non-polar dimer and oligomer) triglycerides (PTG), in the sample is then used for the determination of the Oxidative Stability at Elevated Temperatures (OSET).

OSET value $=[100 /$ Content of PTG in $\%]$

\section{Results and discussion}

During frying fat is exposed to the action of moisture from foodstuff, atmospheric oxygen and high temperatures $\left(140-180^{\circ} \mathrm{C}\right)$. The moisture brings about hydrolytic reactions which give rise to free fatty acids, monoglycerides, diglycerides and glycerol. Many published results indicate that using deep-fat frying, oxidation and polymerisation reactions were more prevalent than hydrolytic reactions.

However, it has been described [13] that quantitation of diacylglycerols, but not of free fatty acids, allows the determination of the contribution of hydrolytic alteration, because these compounds remain in the frying fat while free fatty acids are partially lost by steam distillation during frying. No significant variations were found for diacylglycerol concentrations throughout the successive fryings $[14,15]$.

In the presence of atmospheric oxygen, oxidation is the main reaction to give rise to oxidiz-ed monomers, unpolar dimers and polymers [16]. Generally, dimers of fatty acids, tocopherols or sterols formed by peroxidation are linked by oxygen bridges. The mechanism for these oxidations [17] is initiated by the abstraction of a hydrogen atom by an oxidizing radical from an unsaturated chain. The radical rearranges to form a more stable conjugated system which in presence of oxygen reacts rapidly to form a peroxyl radical and generat-ing a lipid hydroperoxide or other non-radicals.

During the actual frying operation, as oxygen supply is rather limited by steam blanketing from food, the main reactions lead to polymerisation rather than oxidation.

Besides the radical mechanism for the lipid peroxidation and polymerisation of triglycerides another non radical mechanism for the formation of non-oxidised dimers and cyclic triglycerides was proposed by Brütting and Spitteller [18] (Figures $1 a$ and $b$ ). 
The initial reaction is the formation of conjugated fatty acids as there are more reactive than fatty acids with isolated trans double bonds. Hydroperoxides of unsaturated fatty acids (which are also formed by lipid peroxidation) are transformed to conjugated fatty acids. But also in an acid-catalysed reaction polyunsaturated fatty acids may be directly transformed to conjugated fatty acids, which predominately undergo a Diels-Alder reaction. Brütting and Spiteller [18] did not find such Diels-Alder products in their investigations with methyl esters of linolenic and linolic acid. Their results support the hypothesis that the dimerisation of unsaturated fatty acids can also be initated by a cationic mechanism. The intermediately built cationic reaction products are stabilised by mesomeric effects to undergo further reactions to form non-oxygen linked dimers.

The formation of steradienes a similar mechanism has to be assumed, as by acid catalysis at already $90^{\circ} \mathrm{C}$ a small quantity of sterols is dehydrated (elimination) to the corresponding steradienes. Through nucleophilic substitution the corresponding disteryl ether is being formed (Figure 2) [19]. The formation of steradienes during bleaching depends on the added bleach-ing earth and its acidity and moisture $[19,20]$. Without activation with acidic bleaching earths steradienes are not formed at temperatures lower than $150^{\circ} \mathrm{C}[21,22]$.

The effect of free and esterified sterols [23, 24], sesame oil [25] and other naturally occurring substances on the stability of heated oils has been often described and proven. However, Gordon and Williamson [26] confirmed the ineffectiveness of avenasterol as an antioxidant at ambient temperature and under accelerated test conditions in a Rancimat at $100^{\circ} \mathrm{C}$.

It may be that a radical peroxidation mechanism predominates at lower temperatures and nonradical reaction like elimination (acid catalysed dehydration) or nucleophilic substitution at the elevated temperatures of frying. The probability of two different mechanisms may give an answer to the different efficacies of antioxidants at room temperature and during frying process. Common antioxidants, including tocopherols, butylated hydroxyanisole (BHA), propylgallate (PG) and tertiary butylated hydroquinone (TBHQ) retard oxidation at ambient temperatures, but they become substantially less effective or even inactive when subjected to elevated temperatures [27].

Nienhaber et al. [28] observed an antioxidative effect in the fraction of low molecular colourless Maillard reaction products. These reductones are formed by amino acids and carbohydrates following an acid catalysed elimination (1,3-desoxyosone) at elevated temperature or a radical mechanism (glucosone) [29] at $50-80^{\circ} \mathrm{C}$. This observation may explain the fact that the degradation of deep-frying fat runs slower when food is prepared in the fryer than without food.

These facts provide the idea to simulate the reaction of an acid catalysed fat degradation in a model system to check the behaviour of vegetable oils with or without adding antioxidative components at frying temperature.

The dimerisation of unsaturated acids from tall oil, soybean oil or technical oleic acid occurs at 230$260^{\circ} \mathrm{C}$ with a montmorillonite clay as a catalyst $[30,31]$.This reaction is used in the production of dimeric fatty acids. Brat et al. [32] investigated the kinetic of this reaction and found out that the addition of $1-2 \%$ water, $4-6 \%$ Bentonite during heating for 2-8 hours is the optimum. Instead of bleaching earth, silica is used and added to the vegetable oil before heating at $170^{\circ} \mathrm{C}$. Silica was 
adjusted with water to simulate the effect of the moisture of foodstuff. The analyses of deep-fat fried samples have shown that the determination of polymer triglycerides (PTG) is a reliable method to describe the thermal degradation of heated fats. Our initial experimental work showed that heat treatment of oils for two hours at $170^{\circ} \mathrm{C}$ was sufficient to establish the formation of polymers analytically.

Figure 3 shows the protective effect of nitrogen, dimethylpolysiloxane (E900), in a steady state, and inorganic materials on the formation PTG in two oils (1) RBD normal sunflower oil and (2) RBD rapeseed oil. Obviously, as expected, polymers are still being formed in the oils due to heat treatment excluding air.

Compounds like sterols, sesamolin, ascorbyl palmitate are almost inactive at temperatures lower than $120^{\circ} \mathrm{C}$. Therefore, it is believed that, when a large volume of oil is heated in a fryer, the oxygen supply is rather poor. The reactions lead to non-radical catalysed polymerisation rather than oxidation products and the interaction with the secondary products, which are already formed by autoxidation at lower temperatures. Obviously, the amount of steam development controls the type of reaction occurring during the frying operation.

Table 1 gives data of various oxidative stability tests, \% total polar materials (TPM), \% PTG, OSET index, and fatty acid composition of seven formulated oil blends. These oil blends comprised saturated fatty $21.5-60.1 \%$ and trans fatty acids $2.5-39 \%$. The sensory evaluations, after intermittent frying of French fries in these oil blends are also included in the table. The results show that OSET index, TPM or \% TPG gives good correlation with sensory data collected from actual frying tests of French fries in these oil blends. The Rancimat test at $100^{\circ} \mathrm{C}$ and relative oxidatibility calculated according to Pardun [33] (Table 2) using factors for the saturated, unsaturated and polyunsaturated fatty acids gave only indicative information or poor relationship with the sensory results. The fatty acid compositions of the vegetable oils also do not give realistic information about their oxidative stability. It is thus suggested that the minor components, which may be pro-oxidant or antioxidant, present in these oil blends have strong influence on their oxidative stability, especially at frying temperatures.

The acid catalysed polymerisation of triglycerides during deep-frying is obviously retarded by other acid catalysed reactions of sterols, other natural components (sesamolin) and ascorbyl palmitate (Figure 4) which need less activation energy than the dimerisation of triglycerides.

The effects of several synthetic and natural antioxidants on the oxidative stability of refined sunflower oil and rapeseed oil are given in Figures $5 a$ and $b$ respectively. The data show that the presence of natural substances such as squalene, sterol fraction, quercetin, oryzanol, and ferulic acid enhances the stability of vegetable oils at higher temperature. Blekas et al. [34]. demonstrated that both free sterols and steryl esters have similar effects in reducing the deterioration of heated oils. Fedeli [35] and Andrikopoulos et al. [36] reported that during domestic deep frying of potatoes virgin olive oil shows a remarkable stability in comparison to other vegetable oils.

Nevertheless, a radical mechanism for the antioxidant activity of sterols has often been proposed [37].

The transformation of sesamolin to sesamol and sesamin in the presence of acids and water has 
been described by Kamal-Eldin et al. [25]. It is a well-known fact that crude sesame oil is very stable at frying temperature because sesame seed contains the most powerful antioxidants among oil plants.

Some antioxidant and antipolymerisation activity at frying temperatures for alpha-oryzanol a basic constituent of rice bran oil have also been described. Ferulic acid is a methylated ortho-diphenol and its activity has been reported by many investigators.

Certain synthetic components e.g. ascorbyl palmitate and gallates also increase the oxidative stability of the oils studied. It is, however, thought that the quantity of the antioxidant component, its synergism with other natural antioxidants present, the type of food being fried and applied temperature would have also some role in the overall stabilising effect on oil stability at elevat-ed temperature. Rancimat failed to check the antipolymersation properties of sterols, orycanol or ascorbyl palmitate at elevated temperature (see also Figure $5 a$ and $b$ ). Therefore, under frying conditions a cationic catalysed mechanism has to be assumed for the effectiveness of these compounds instead of a radical mechanism. Table 2 presents the results of the oxidative stability of commercially available fats and oils. Non-refined, "Virgin" vegetable oils showed remarkably better stability at frying temperature than that given by the corresponding refined oils. These findings are in good agreement with the literature information that refining of oils and fats results in removal of considerable amounts of antioxidative potent components, thus lowering their natural oxidative stability.

After a storage time of several months, the same sample sunflower oil (Table 2) demonstrates a loss of stability. Conjuenic fatty acids as pre-cursors of the dimerisation of triglycerides can be formed by autoxidation and acid catalysed reaction.

\section{CONCLUSION}

It may be, which is possible, that a radical peroxidation mechanism predominates at lower temperature, while a complex set of non radical, acid catalysed chemical reactions occur predominantly at frying temperatures during actual frying operation.

The probability of two different mechanisms may provide an answer to the different antioxidative activity of natural minor components like sterols or synthetic components such as BHA, ascorbyl palmitate.

OSET index is a good parameter for evaluating heat stability of frying fats and oils at frying conditions.

The OSI or Rancimat method can give misleading or poor information about heat stability of frying fats and oils at the temperature of frying.

The fatty acid composition data of an oil or fat give only indicative information about its oxidative stability. The addition or naturally presence of antioxidative components and their synergistic power in the oil exerts strong influence on its heat stability. 


\section{REFERENCES}

1. PARDUN H, KROLL E (1972). Bestimmung der Oxydationsstabilität von Ölen und Fetten mit Hilfe einer automatischen Version des Swift-Testes. Fette Seifen Anstrichmittel Die Ernährungsindustrie, 74: 366-72.

2. HADORN H, ZÜRCHER K (1974). Zur Bestimmung der Oxydationsstabiltät von Ölen und Fetten. Deutsche Lebensmittel-Rundschau, 70: 57-65.

3. JEBE TA, MATLOCK MG, SLEETER RT (1993). Collaborative study of the Oil Stability Index Analysis. J Am Oil Chem Soc, 70: 1055-61.

4. AOCS Official Method: Oil Stability Index (OSI) (1997). Cd 12-92.

5. LÄUBLI MW, BRUTTEL PA, SCHALCH E (1988). Bestimmung der Oxidationsstabilität von Fetten und Ölen-Vergleich zwischen der Active Oxygen Method (AOCS Cd 12-57) and der Rancimat-Methode. Fat Sci Technol, 90: 56-8.

6. BURKOW IC, VIKERSVEEN L, SAAREM K (1995). Evaluation of antioxidants for cod liver oil by chemiluminescence and the rancimat method. J Am Oil Chem Soc, 72: 553-7.

7. LÄUBLI MW, BRUTTEL PA (1986). Determination of the oxidative stability of fats and oils: comparison between the active oxygen method (AOCS Cd 12-57) and the Rancimat method. J Am Oil Chem Soc, 63: 792-5.

8. OHSHIMA T, FUJITA Y, KOIZUMI C (1993). Oxidative stability of sardfine and mackerel lipid with reference to synergism between phospholipids and alpha-tocopherol. J Am Oil Chem Soc, 70: 269-76.

9. CROSS CK (1970). Oil stability: a DSC alternative for the active oxygen method. J Am Oil Chem Soc, 47: 229-30.

10. KOWALSKI B, GRUCZYNSKA E, MACIASZEK K (2000). Kinetics of rapeseed oil oxidation by pressure differential scanning calorimetry measurements. Eur J Lipid Sci Technol, 202: 337-41.

11. GERTZ CH (2000). Testing and comparing oxidative stability of vegetable oils and fats at frying temperature. Eur J Lipid Sci Technol, 102: 543-51.

12. GERTZ C, KLOSTERMANN S (2000). A new analytical procedure to differentiate virgin or nonrefined vegetable fats and oils. Eur J Lipid Sci Technol, 102: 329-36.

13. DOBARGANES MC, PÉREZ-CAMINO MC, MÁRQUEZ-RUIZ G (1988). High-performance size exclusion chromatography of polar compounds in heated and non-heated fats. Fat Sci Technol, 90: 308-11.

14. GONZÁLEZ-MUNOZ MJ, TULASNE C, ARROYO R, SÁNCHEZ-MUNIZ FJ (1996). Digestibility and absorption coefficients of palm olein-relationships with thermal oxidation induced by potato frying. Fett/Lipid, 98: 104-8. 
15. ROMERO A, CUESTA C, SÁNCHEZ-MUNIZ FJ (1995). Quantitation and distribution of polar compounds in an extra vergin olive oil used in fryings with turnover of fresh oil. Fat Sci Technol, 97: 403-7.

16. GUTIÉRREZ R, GONZALES-QUIJANO F, DORBARGANES MC (1988). Analytical procedures for the evaluation of used frying fats. In: VARELA G, BENDER AE, MORTON ID, eds. Frying of food. Principles, changes, new aproaches. Chichester, England : Ellis Horwood Ltd.

17. LAMBERT CR (1999). Formation of Free Radicals and Protection Mechanisms in vitro and in vivo. In: BOSKOU D, ELMADFA I, eds. Frying of food. Technolic Publishing Company, Inc. Lancatser Basel.

18. BRÜTTING R, SPITELLER G (1994). Produkte der Dimerisierung ungesättigter Fettsäuren XII: Die Dimerisierung von Konjuenfettsäuren. Fat Sci Technol, 96: 445-51.

19. WEBER N, BERGENTHAL D, BRÜHL L, SCHULTE E (1992). Disterylether-Artefakte der Fettbleichung. Fat Sci Technol, 94: 182-92.

20. GERTZ CH, MEZOUARI S (1996). The Influence of different bleaching earths on the formation of new components in oils. Lebensmittelchemie, 50: 66-7.

21. GROB K, GIUFFRE AM, BIEDERMANN M, BRONZ M (1994). The detection of Adulteration with Desterolized Oils. Fat Sci Technol, 96: 341-5.

22. KOCHHAR SP, MEZOUARI S, EICHNER K, GERTZ CH (1999). Influence of bleaching process on minor components in oils. Paper presented at the 23rd world Congress and Exhibition of the International Society for Fat Research(ISF), 3-7 October, Brighton, England.

23. CHANG SS, MORTON PE (1969). Breakdown inhibitors. In: Bednarcyk NE, ed. Food Processing Review No 5. ed. Noyes Development Corporation, New Jersey: 209-11.

24. GORDON MH, MAGOS P (1984). The effect of sterols on the oxidation of edible oils. Food Chem, 10: 141-7.

25. KAMAL-ELDIN A, APPELQUIST LA, GERTZ CH, STIER RF (1998). Enhancing the frying performance of high oleic sunflower oil using sesame oil and rice bran oil. J Foodservice Systems, 10: 139-57.

26. GORDON MH, WILLIAMSON E (1989). A Comparison of headspace analysis with other methods for assessing the oxidative deterioration of edible oils. In: LIEN WS, FOO CW, eds. Trends in Food Science. Singapore, Singapore Institute of Food Science and Technology: 53-7.

27. CHANG SS, MONE PE (1969). Breakdown inhibitors. In: BEDNARCYCK NE, ed. Food Processing Review No.5. Noyes Development Corporation, New-Jersey: 209-211.

28. NIENABER U, EICHNER K (1995). The antioxidative effect of maillard reaction products in model systems and roasted hazelnuts. Fat Sci Technol, 97: 435-44.

29. LIEDKE R (1999). Bildung von alpha-Dicarbonylverbindungen beim Abbau von AmadoriUmlagerung-Produktion Dissertation University Münster, Germany. 
30. HEIDBREDER A, HÖRER R, GRÜTZMACHER R, WESTFECHTEL A, BLEWETT CW (1999). Oleochemical products as building blocks for polymers. Fett/Lipid, 101: 418-24.

31. BRÜTTING R, SPITTELLER G (1994). Produkte der Dimerisierung ungesättigter Fettsäuren XII. Fat Sci Technol, 96: 445-51.

32. BRAT J, SCHWARZ W, ZAJíC J (1995). Beurteilung der Kinetik der Polymerisation von Fettsäuren. Fat Sci Technol, 97: 513-7.

33. PARDUN H (1974). Beurteilung des Präoxydationsgrades bzw. Oxydationsstabilität pflanzlicher Öle aufgrund ihrer Benzidin- oder Ansidinzahl. Fette Seifen Anstrichmittel, 76: 521-8.

34. BLEKAS G, BOSKOU D (1986). Effect of esterified sterols on the stability of heated oils. In: CHARALAMBOUS G, ed. The shelf life of foods and beverages. Amsterdam: Elsevier: 403-8.

35. FEDELI E (1988). The behaviour of olive oil during cooking and frying. In: VARELA G, BENDER AE, MORTON ID, eds. Frying of food, principles changes, new approaches. Chichester England, VCH: Ellis Horwood: 52-81.

36. ANDRIKOPOULOS NK, TZAMTZIS VA, GIANNOPOULOS GA, KALANTZOPOULOS GK, DEMOPOULOS CA (1989). Deterioration of some vegetable oils I: during heating or frying of several foods. Rev Fr Corps Gras, 36: 127-9.

37. YANISHLIEVA N, SCHILLER H, MARINOVE E (1980). Autoxidation of sitosterol II: main products formed at ambient and high temperature treatment with oxygen. Riv Ital Sost Grasse, 57: 572-6. 


\section{Illustrations}

a

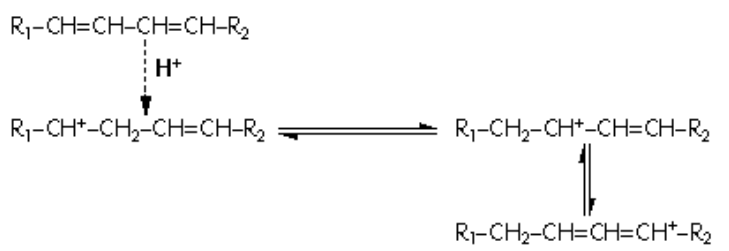

b

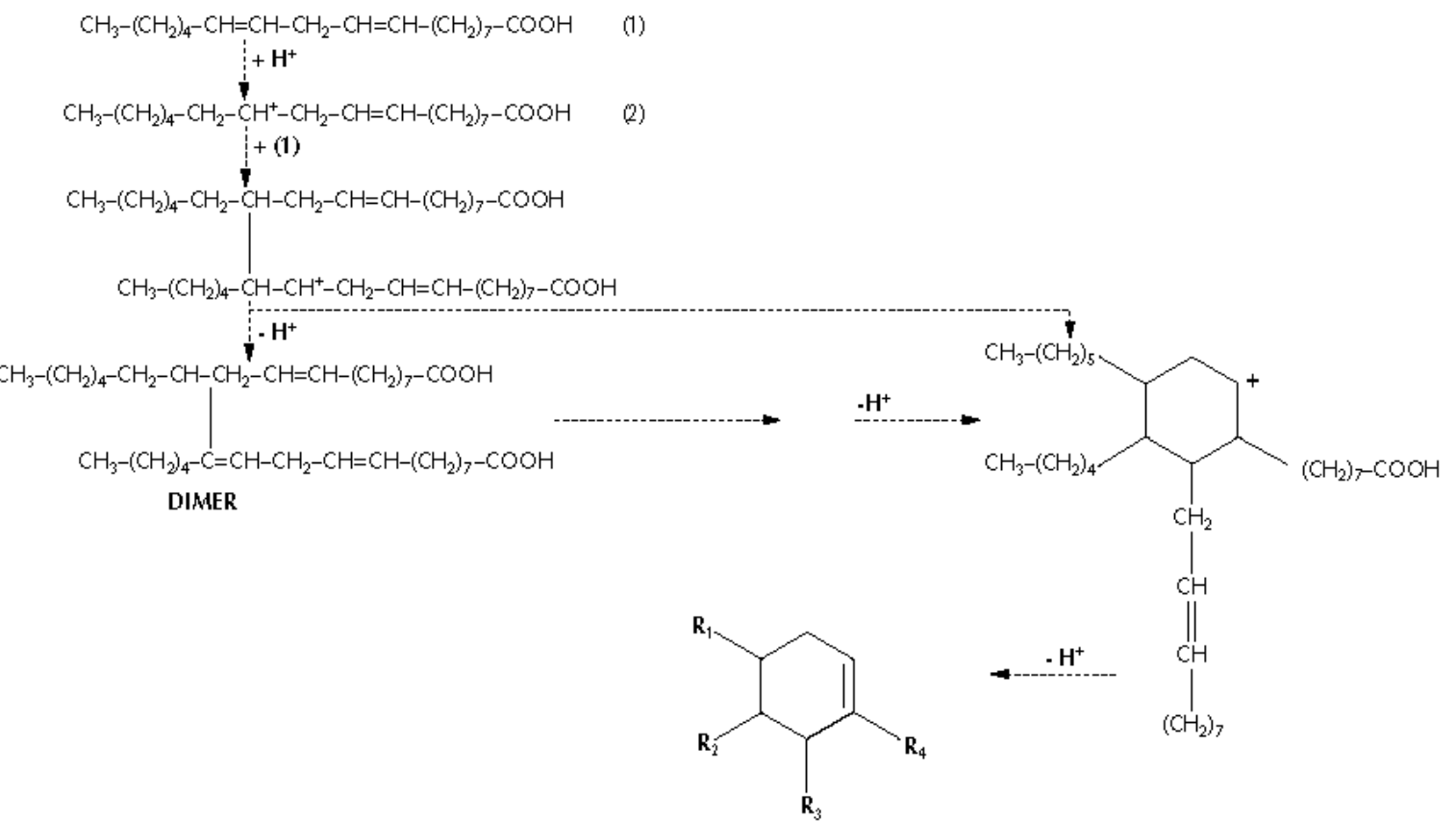

Figure 1a. Protonation of conjugated fatty acids. Figure 1b. Intermolecular formation of dimerised and cyclic linoleic acid. 


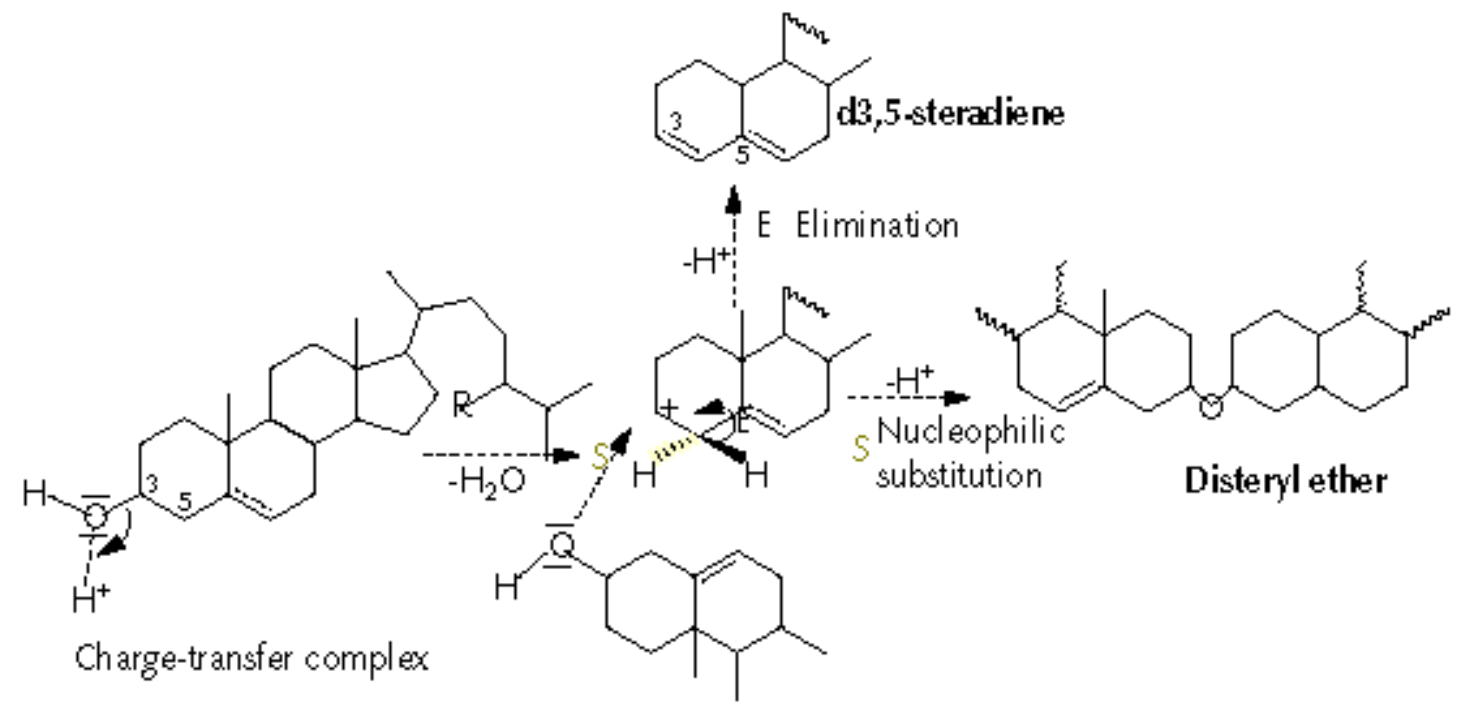

Figure 2. Acid catalysed formation of steradienes and disteryl ether from sterols.

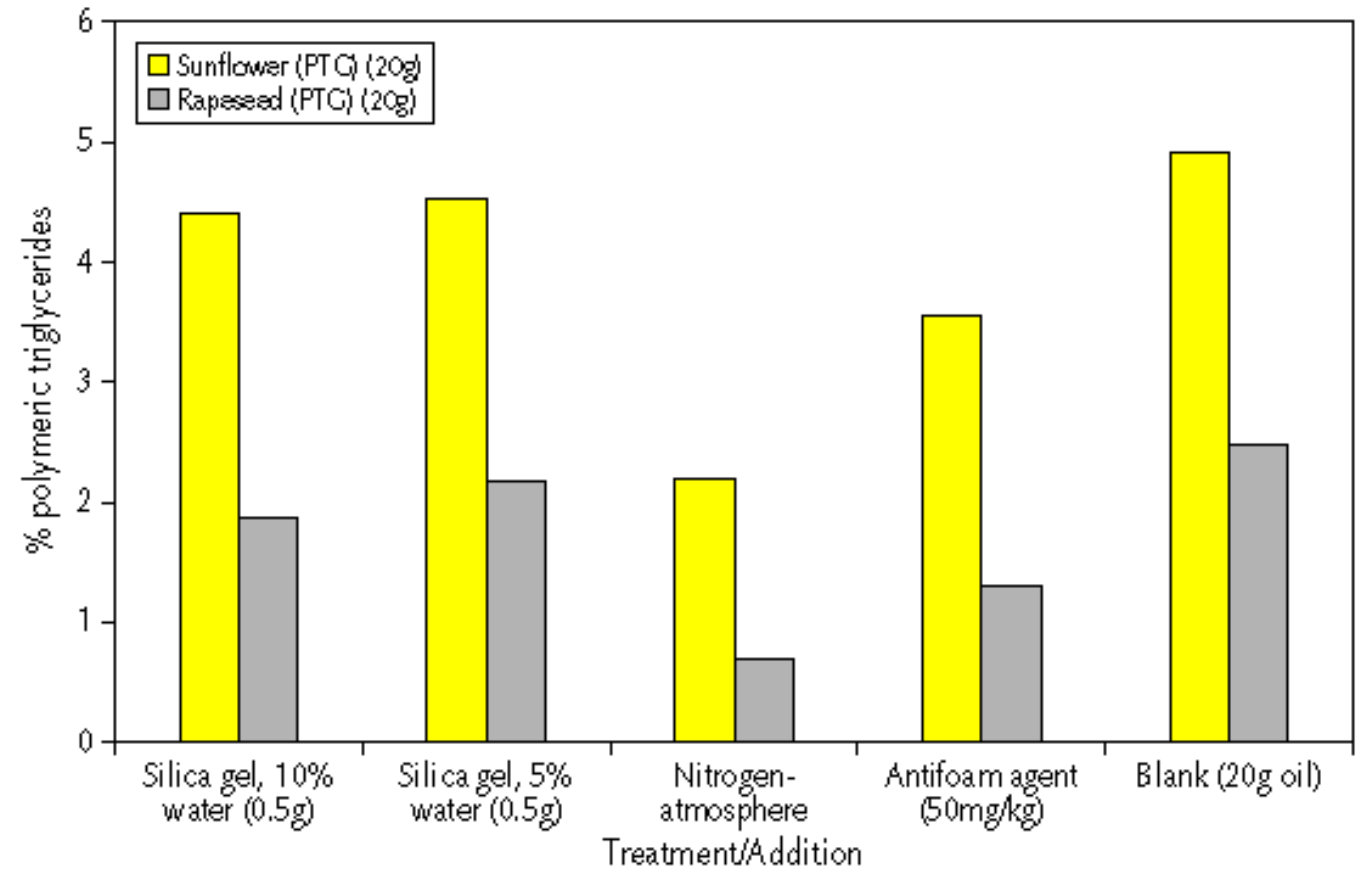

Figure 3. Influence of various procedures and additions on the forming of dimeric triglyerides after heating at $170^{\circ} \mathrm{C} / 2 \mathrm{~h}$. 


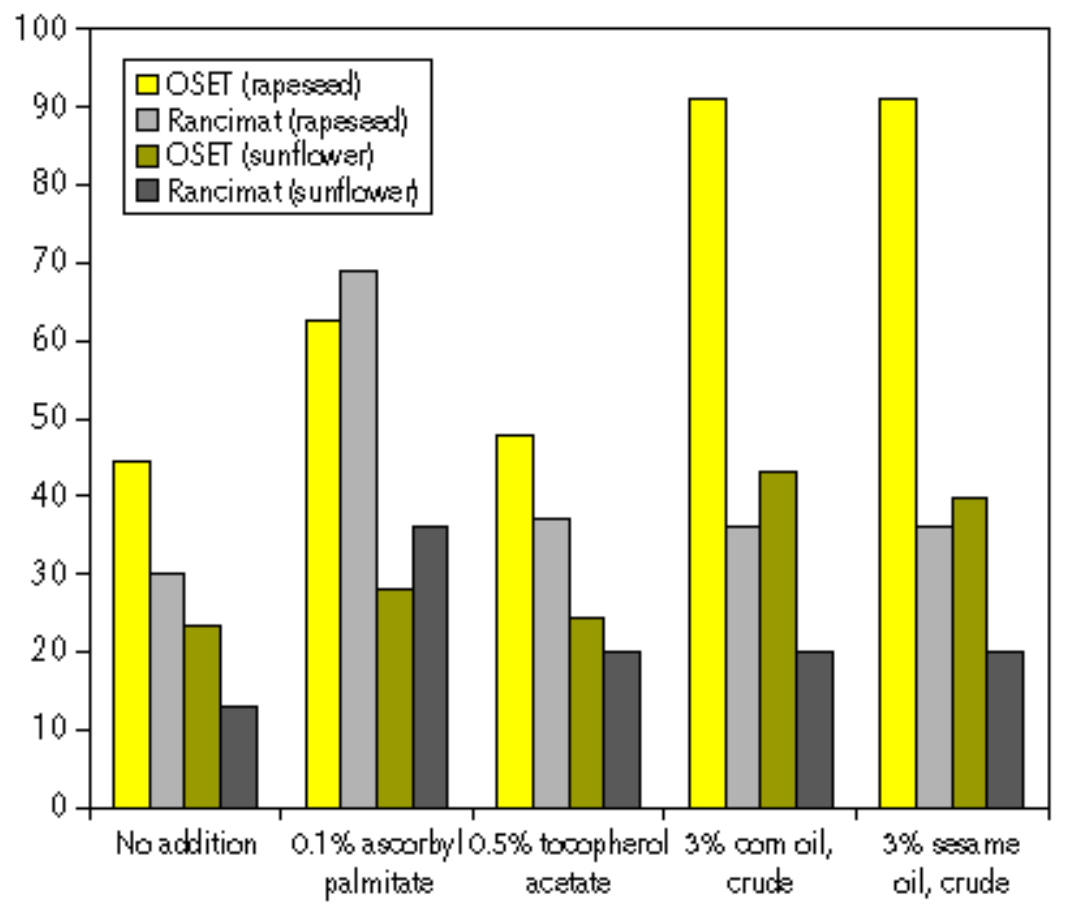

Figure 4. Effectiveness of some natural and synthetic antioxidants measured by Rancimat method $\left(120^{\circ} \mathrm{C}, 2 \mathrm{Ol}\right)$ [h] and OSET. 
a

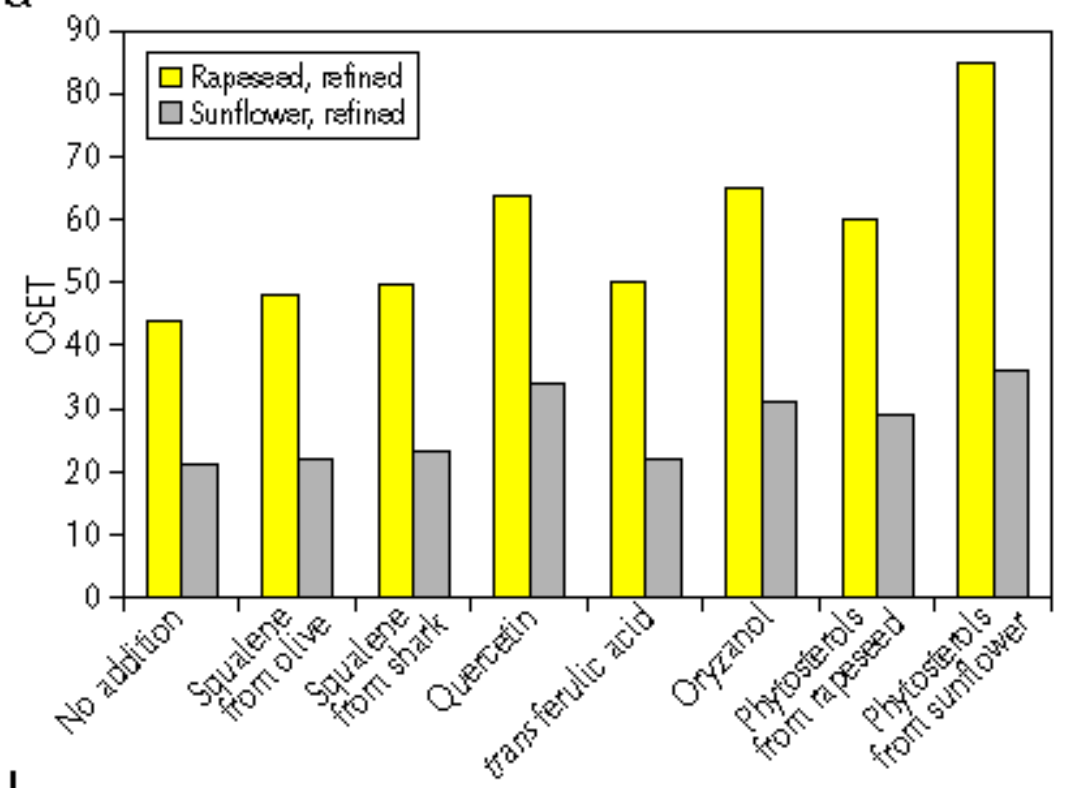

b

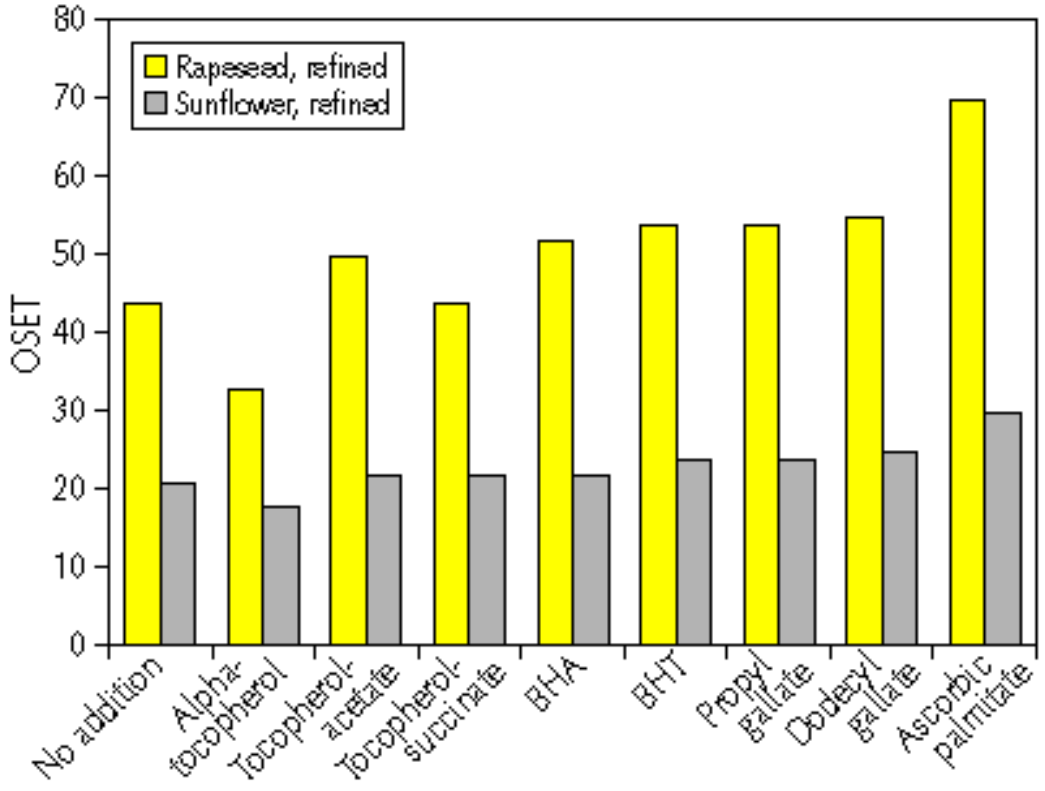

Figure 5a. Effects of natural antioxydants on oxydative stability of refined sunflower and rapeseed oil.Figure 5b. Effects of synthetic antioxydants on oxydative stability of refined sunflower and rapeseed oil. 
Table 1. Comparison of stability tests and fatty acid composition.

\begin{tabular}{|c|c|c|c|c|c|c|c|c|c|c|c|}
\hline \multicolumn{3}{|c|}{ Data } & \multicolumn{4}{|c|}{ Stability } & \multicolumn{5}{|c|}{ Fatty acid composition } \\
\hline Sample & $\begin{array}{c}\text { Sensoric } \\
\text { defects after } \\
\text { (h) }\end{array}$ & $\begin{array}{c}\text { Total polar } \\
\text { compounds } \\
(\%)\end{array}$ & $\begin{array}{c}\text { Swift-Test } \\
\text { (Rancimat) } \\
\left(100^{\circ} \mathrm{C}\right)\end{array}$ & \begin{tabular}{|c|}
$\begin{array}{c}\text { Rel. } \\
\text { oxidbility } \\
\text { (from }\end{array}$ \\
Pardun [33)
\end{tabular} & $\begin{array}{c}\% \text { polymers } \\
\text { after } \\
\text { application } \\
\text { of oxidation- } \\
\text { stability test }\end{array}$ & OSET & Saturates & $\begin{array}{l}\text { Monoenic } \\
\text { acids (trans } \\
\text { included) }\end{array}$ & $\begin{array}{c}\text { Dienic acids } \\
\text { (trans } \\
\text { included }\end{array}$ & \begin{tabular}{|c|} 
Trienic acids \\
(trans \\
included)
\end{tabular} & $\begin{array}{c}\text { Trans-fatty } \\
\text { acid }\end{array}$ \\
\hline 1 & 14 & 16 & 25.40 & 153 & 2.53 & 40 & 60.1 & 23.6 & 15.3 & 1 & 2.5 \\
\hline 2 & 18 & 18.7 & 45.50 & 149 & 1.92 & 52 & 56 & 33 & 9 & 2 & 5 \\
\hline 4 & 27 & 26.1 & 40.00 & 148 & 1.88 & 53 & 48 & 42 & 8.5 & 1.5 & 11 \\
\hline 5 & 27 & 24.2 & 47.00 & 160 & 1.79 & 56 & 21.5 & 70 & 8 & 0.5 & 18.9 \\
\hline 6 & 30 & 26.7 & 51.00 & 150 & 1.67 & 60 & 22.5 & 68 & 7 & 2.5 & 36 \\
\hline 3 & 24 & 23.9 & 56.40 & 159 & 1.64 & 61 & 40.5 & 47 & 10 & 2.5 & 10.8 \\
\hline 7 & 26 & 28.6 & 65.00 & 139 & 1.63 & 61 & 25.5 & 68 & 5.5 & 1 & 39 \\
\hline
\end{tabular}


Table 2. Heat stability of commercially available fats and oils.

\begin{tabular}{|c|c|c|c|c|c|c|}
\hline \multirow[t]{2}{*}{ Vegetable oil } & \multirow[t]{2}{*}{ OSET } & \multirow{2}{*}{$\begin{array}{c}\text { Re I. oxidation } \\
\text { stability (fram Pardun [33]) }\end{array}$} & \multirow[b]{2}{*}{ Saturated } & \multicolumn{2}{|c|}{ Fatty acid com pos ition } & \multirow[b]{2}{*}{ Trans } \\
\hline & & & & Monoenic & Polyenic & \\
\hline Deep frying fat ${ }^{*}$, refined & 61 & 152 & 49.8 & 40.0 & 9.7 & 0.5 \\
\hline Deep frying fat ${ }^{*}$, refined & 60 & 149 & 52.4 & 36.7 & 9.6 & 1.4 \\
\hline Deep frying fat ${ }^{*}$, refined & 44 & 152 & 50.7 & 38.5 & 10.1 & 0.7 \\
\hline Deep frying oil ${ }^{*}$, refined & 43 & 221 & 15.5 & 42.1 & 41.6 & 0.8 \\
\hline Deep frying fat ${ }^{*}$, refined & 38 & 150 & 51.3 & 38.1 & 9.2 & 1.4 \\
\hline Deep frying fat ${ }^{*}$, refined & 36 & 149 & 51.7 & 38.1 & 8.8 & 1.4 \\
\hline Deep frying oil ${ }^{*}$, refined & 36 & 253 & 10.7 & 25.5 & 63.1 & 0.7 \\
\hline Deep frying oil ${ }^{*}$, refined & 34 & 231 & 16.2 & 34.6 & 49.0 & 0.3 \\
\hline Deep frying oil ${ }^{*}$, refined & 31 & 253 & 10.8 & 25.1 & 63.5 & 0.6 \\
\hline Deep frying oil*, refined & 30 & 251 & 12.2 & 24.6 & 62.6 & 0.6 \\
\hline Deep frying oil ${ }^{*}$, refined & 29 & 253 & 10.7 & 25.2 & 63.5 & 0.6 \\
\hline Deep frying oil ${ }^{*}$, refined & 27 & 253 & 10.6 & 25.4 & 63.3 & 0.7 \\
\hline "Wok oil" ${ }^{\mathrm{m}}$, refined & 52 & 247 & 12.8 & 26.3 & 59.7 & 1.2 \\
\hline Vegetable oil, refined & 42 & 243 & 13.3 & 28.9 & 57.3 & 0.6 \\
\hline Vegetable oil, refined & 27 & 253 & 10.7 & 25.6 & 63.1 & 0.6 \\
\hline Vegetable oil, refined & 25 & 267 & 10.5 & 14.0 & 74.1 & 1.4 \\
\hline Olive oil, virgin & 45 & 181 & 12.5 & 78.8 & 8.7 & 0.0 \\
\hline Saflower oil, non refined & 30 & 263 & 11.9 & 17.2 & 70.9 & 0.1 \\
\hline Saflower oil & 27 & 256 & 25.8 & 0.0 & 74.2 & 0.1 \\
\hline Saflower oil & 25 & 263 & 11.4 & 17.3 & 70.8 & 0.5 \\
\hline Ground nut oil, non refined & 49 & 198 & 22.4 & 49.8 & 27.6 & 0.2 \\
\hline Ground nut oil & 32 & 215 & 17.7 & 42.1 & 38.6 & 1.6 \\
\hline Ground nut oil & 32 & 185 & 18.7 & 65.2 & 15.8 & 0.3 \\
\hline Ground nut oil & 29 & 216 & 17.8 & 41.7 & 39.1 & 1.4 \\
\hline Rapseed, non refined & 109 & 208 & 8.2 & 65.0 & 26.5 & 0.3 \\
\hline Raspeed, refined & 51 & 208 & 8.1 & 64.8 & 26.8 & 0.3 \\
\hline Raspeed, refined & 32 & 207 & 8.3 & 65.1 & 26.3 & 0.3 \\
\hline Sesame oil, crude & 78 & 223 & 16.2 & 40.2 & 43.5 & 0.1 \\
\hline Sesame oil, refined & 38 & 222 & 16.6 & 40.7 & 42.6 & 0.1 \\
\hline Grape oil, refined & 27 & 261 & 11.3 & 17.5 & 70.1 & 1.1 \\
\hline Com oil, refined & 51 & 241 & 14.0 & 30.4 & 55.4 & 0.2 \\
\hline Com oil, refined & 50 & 243 & 13.7 & 28.8 & 57.0 & 0.5 \\
\hline Com oil, refined & 47 & 243 & 13.6 & 28.8 & 57.0 & 0.6 \\
\hline Sunflower, non refined & 46 & 261 & 11.8 & 18.6 & 69.5 & 0.1 \\
\hline Sunflower, refined (Peroxid value: 2 ) & 27 & 255 & 12.9 & 21.6 & 65.4 & 0.1 \\
\hline Sunflower, refined (Peroxid value: 10 ) & 22 & 251 & 11.1 & 26.6 & 61.5 & 0.8 \\
\hline Soybean oil, refined & 39 & 242 & 16.4 & 24.7 & 58.3 & 0.7 \\
\hline Almond oil, refined & 36 & 207 & 8.3 & 65.2 & 26.3 & 0.2 \\
\hline Walnut, non refined & 109 & 267 & 9.4 & 17.7 & 72.8 & 0.1 \\
\hline Walnut, refined & 52 & 263 & 10.4 & 17.1 & 71.2 & 1.3 \\
\hline Linseed oil, non refined & 66 & 264 & 10.0 & 18.7 & 71.0 & 0.3 \\
\hline Avocado oil, refined & 36 & 182 & 21.6 & 62.8 & 15.2 & 0.4 \\
\hline Palmoil, refined & 48 & 158 & 44.8 & 43.6 & 11.1 & 0.5 \\
\hline Pumkin seed oil, virgin & 112 & 236 & 19.4 & 25.8 & 54.7 & 0.1 \\
\hline Pumkin seed oil, refined & 62 & 236 & 18.3 & 26.9 & 54.7 & 0.1 \\
\hline
\end{tabular}

- These products were labelibd as extremely resistant agairst heat. 